\title{
Efficiency of community health service in urban and suburban areas of Shanghai: based on production function
}

\author{
AN ZHANG ${ }^{1}$, WEN XIA ${ }^{2}$, YONG BAO ${ }^{3}$
}

\section{Abstract}

Objective: To analyze the efficiency of community health service in urban and suburban areas of Shanghai.

Methods: Fifty community health centers in Shanghai that registered to create "National Demonstration Community Health Center" in 2013 were included in our study. The service efficiency was analyzed with the methods of econometrics based on Cobb-Douglas production function.

Results: Two production functions were formulated for urban community health services and those in suburban areas; the equation for urban areas was: $\ln Y=7.778+0.450 \ln L+0.350 \ln \mathrm{K}+\mu$; and the equation for suburban areas was: $\ln Y=6.329+0.728 \ln L+0.350 \ln K+\mu$. The results showed that among the inputs, labor had more effect on output than capital did. It also showed that marginal benefit of labor was different in urban and suburban areas. Urban community health centers were in the interval of decreasing returns to scale, while suburban community health centers were in the interval of constant returns to scale.

Conclusion: Increasing human resource investment is a key factor for increasing community health service output. Due to the difference of scale merit between urban and rural areas, government or other policy makers should make the development policy for them accordingly. Those community health centers in urban areas should pay more attention to the service efficiency and service innovation.

Keywords: Community health service, Urban, Suburban, Production function, Efficiency

\section{Introduction}

To enhance the construction of community health centers in Shanghai, fulfill the core tasks of medical reform, and to implement the Notification on Constructing National Demonstration Community Health Centers released by National Health and Family Planning Commission of China [1], the activity of constructing national demonstration community health centers was carried out from 2011 to 2013. This study is aimed to analyze the characteristics of 50 community health centers participated in the activity, and to evaluate their service efficiency, which may provide some valuable information for policy making.

\section{Methods}

Subjects

A total of 57 community health centers participated in the activity mentioned above in Shanghai, of which 50 were included in this study, while the other 7 were excluded for lack of information. Among the 50 centers, 18 were in urban areas and 32 were in suburban areas,
1. Antai College of Economics and Management, Shanghai Jiao Tong University, Shanghai 200052, China

2. Shanghai Municipal Center for Disease Control and Prevention, Shanghai 200336, China

3. School of Public Health, Shanghai Jiao Tong University, Shanghai 200025, China

CORRESPONDING AUTHOR: Yong Bao

School of Public Health, Shanghai Jiao Tong University, Shanghai, 200025, China 13651673015@139.com

Funding: This research received no specific grant from any funding agency in the public, commercial, or not-for-profit sectors. 
Table1. The Administrative Area distribution of 50 Community Health Centers

\begin{tabular}{|llllll}
\hline District or County & No.* & District or County & No. & District or County & No. \\
\hline Huangpu & 1 & Hongkou & 2 & Jiading & 4 \\
\hline Jing'an & 3 & Yangpu & 3 & Songjiang & 3 \\
\hline Changning & 1 & Jinshan & 3 & Minhang & 4 \\
\hline Putuo & 2 & Baoshan & 4 & Fengxian & 3 \\
\hline Xuhui & 4 & Pudong & 8 & Qingpu & 1 \\
\hline Zhabei & 2 & Chongming & 2 & & \\
\hline
\end{tabular}

* No.=the number of community health centers

covering all 17 counties of Shanghai (see Table 1).

\section{The production function \\ Cobb-Douglas production function}

Some core elements in economics were involved in the simple form of CobbDouglas production function, and the function is widely used to represent the technological relationship between the amounts of two or more inputs, particularly physical capital and labor, and the amount of output that can be produced by those inputs.

Its basic form is $\mathrm{Y}=\mathrm{AL}^{\alpha} \mathrm{K}^{\beta} \mu$, where $\mathrm{Y}$ stands for total production, $\mathrm{A}$ is technical efficiency, $\mathrm{L}$ is labor input, $\mathrm{K}$ is capital input, $\alpha$ and $\beta$ are the output elastic coefficients of capital and labor, respectively, and $\mu$ is the random effect of confounding factors. This function shows that the main determinants of the development of community health service are labor input, capital input, and technology level (including the management level of the business, labor quality, and the introduction of advanced technology). Output elastic coefficients $\alpha$ and $\beta$ measure the responsiveness of output to a change in levels of either labor or capital used in production, ceteris paribus. According to the value of $\alpha$ and $\beta$ combination, there are three types of Cobb-Douglas production function: If $\alpha+\beta>1$, returns to scale are increasing[2], meaning that increasing the usage of capital $\mathrm{K}$ and labor L will bring more increase in output; in other words, it's worthy to increase the usage of capital and labor. If $\alpha+\beta<1$, returns to scale are diminishing, meaning that increasing the usage of capital and labor will not improve the efficiency of production. And if $\alpha+\beta=1$, the production function has constant returns to scale, meaning that doubling the usage of capital $\mathrm{K}$ and labor $\mathrm{L}$ will also double output $\mathrm{Y}$, and the production efficiency could be improved only through improving the technology they applied[3].

\section{Variables}

In this study, there were two types of variables, input variables and output variables. The inputs included the capital input and labor input. Capital input referred to the sum of expenditure of the community health center, subsidy of public health in community, prepaid expense of health insurance, the subsidy from the higher organs, and other income (unit: thousand Yuan RMB); labor input referred to the number of medical workers including doctors, nurses, medical technicians and so on (unit: person).
As community health service was part of the social welfare, the service output can be measured by the quantity of services they could provide, including number of outpatient visits, patient bed days, health records filed, chronic disease management, health maintenance of the special population, prophylactic vaccination and family planning advice, and so on. Due to the differences of time consumed and technical difficulty among the kinds of services, the total amount of services was calculated with the methods reported by Liu et al. [4] and Peng et al.[5]. The standard weight coefficients of each kind of service were brought forward with the consideration of integrated factors including location, time consumed, technical difficulties, and risk of the services. For example, taking outpatient visits as the reference, the coefficients of home visit, patient bed day, and vaccination would be 2, 3, and 1, respectively. Then the amount of annual output of the health center was determined (unit: person-time).

\section{Statistical analysis}

The coefficients of the production function were calculated with Eviews 6.0. Ordinary least square (OLS) was performed to estimate the value of $\mathrm{A}$, and weighted least square (WLS) was performed to estimate the value of $\alpha$ and $\beta$. Wald tests were used to compare the two equations in urban and suburban areas.

\section{Results \\ Production functions of urban and suburban community health service in Shanghai}

Log transformation was used to convert 
Table 2. The result of WLS for Urban Community Health Service in Shanghai

\begin{tabular}{lllll}
\hline Variables & Coefficient & SE & $t$ & $P$ \\
\hline $\operatorname{lnL}$ & 0.455 & 0.049 & 9.178 & 0.000 \\
\hline $\operatorname{lnK}$ & 0.350 & 0.029 & 11.992 & 0.000 \\
\hline
\end{tabular}

Note: SE: standard error; $\ln A$ (constant) $=7.778, \mathrm{R}^{2}=0.952, F=149.909, P=0.000$

Table 3. The result of WLS of Suburban Community Health Service in Shanghai

\begin{tabular}{lllll}
\hline Variables & Coefficients & SE & $t$ & $P$ \\
\hline $\operatorname{lnL}$ & 0.728 & 0.091 & 7.953 & 0.000 \\
\hline $\operatorname{lnK}$ & 0.350 & 0.057 & 6.137 & 0.000 \\
\hline
\end{tabular}

Note: SE: standard error; $\ln \mathrm{A}$ (constant) $=6.320, \mathrm{R}^{2}=0.941, F=231.878, P=0.000$

Cobb-Douglas function to linear model with less heteroscedaticity. The function was as below:

$\ln \mathrm{Y}=\ln \mathrm{A}+\alpha \times \ln \mathrm{L}+\beta \times \ln \mathrm{K}+\mu$. Assuming $\ln \mathrm{Y}=\mathrm{Y}^{*}, \ln \mathrm{A}=\mathrm{A}^{*}, \ln$ $\mathrm{L}=\mathrm{L}^{*}, \ln \mathrm{K}=\mathrm{K}^{*}$, the function will be $\mathrm{Y}^{*}=\mathrm{A}^{*}+\alpha \mathrm{L}^{*+}+\beta \mathrm{K}^{*}+\mu$.

The WLS was performed with Eviews 6.0. The equation of urban community health service was:

$\ln \mathrm{Y}=7.778+0.455 \ln \mathrm{L}+0.350 \ln \mathrm{K}+\mu$, see Table 2. In this equation, the coefficients of $\ln \mathrm{L}$ and $\operatorname{lnK}$ were all at significant level $(P<0.005)$. Goodness of fit (also called the coefficient of determination) $R^{2}\left(R^{2} \leq 1\right)$ describes how well the statistical model fits a set of observations. The higher $\mathrm{R}^{2}$ is, the more the dependant variable can be explained by the independent variable [6]. In this model, the $\mathrm{R}^{2}$ was 0.952 , which also indicated the model was a satisfactory one.

The equation of suburban community health service was:

$\ln \mathrm{Y}=6.320+0.728 \ln \mathrm{L}+0.350 \ln \mathrm{K}+\mu$, see Table 3. The coefficients of $1 \mathrm{~nL}$ and $\operatorname{lnK}$ were all at significant level $(P<0.005)$. In this model, the $\mathrm{R}^{2}$ was 0.941 , showing that the model was a satisfactory one.

\section{The scale effect of community health} service in urban and suburban areas In the function of urban community health service, $\alpha+\beta=0.455+0.350=0.805$, the value of which reflected the scale of the economies. The Wald test showed that $\alpha+\beta$ was significantly lower than 1 $(F=14.55, P=0.0017)$.

In the function of suburban community health service, $\alpha+\beta=0.728+0.350=1.078$. The Wald test showed that there was no significant difference between $\alpha+\beta$ and $1(F=1.80$, $P=0.1)$.

\section{Discussion}

The models of urban and suburban community health service in Shanghai show that labor input contributes more to the service output than capital input does. In specific, the marginal benefits of labor input were 0.455 and 0.728 respectively in urban model and suburban model, which were higher than those of capital input $(0.350,0350)$. The effect of labor input on the service output was even stronger in suburban model, in which model a $1 \%$ increase in labor usage would lead to approximately a $0.728 \%$ increase in service output. This result indicates that human resource is the fundamental element of community health service, the quality and quantity of which determine the quality of services in the region [7]. This result is consistent with the finding of the authors' other study [8]. The effect of labor input on the service output was stronger in suburban areas than in urban areas. It illustrates that the shortage of medical workers is more severe in suburban areas, which can be also proved by the interviews with the staff from suburban community health centers. It is more difficult for suburban community health centers to attract and retain medical talents.

As human resource is essential for the improvement of service efficiency in community, the training of medical staff should be strengthened. The medical staff training should cover not only general practitioners but also nurses, staff of public health and so on. Based on the existing training system, a more comprehensive and standard medical training system including resident physicians training model, training evaluation system, and so on should be developed. To attract more medical talents, more flexible and innovative policy should be formulated. For example, community health centers could provide their staff more flexibility regarding the time, location and methods of working, with less emphasis on the Hukou (registered residence), personnel records, personnel relationships and so on. Also the multiple systems of rewards and punishment 
can be developed by providing the staff more opportunities of training, further education, and international and domestic communication.

This study depicted the development model of community health service in Shanghai, which can provide some empirical data for policy making. The results indicate that urban community health centers are in the interval of decreasing returns to scale, where doubling the usage of labor input and capital input can increase the output by less than $100 \%$. Under the current circumstance, increasing the labor or capital input will not increase the service efficiency in urban areas. The main factors impairing the service efficiency might be the deficiencies in management of staff, operation model, decision making, and so on. Only by changing the management model and introducing more advanced technology can the service efficiency boost. However, suburban community health centers in our study are in the interval of constant returns to scale, where doubling the usage of labor input and capital input will also double the service output. It indicates that the community health service in suburban areas can improve through increasing the investment in them. Since 2012, ten communities in Shanghai such as Pudong, Zhabei, and others have put forward family doctor services in their community health centers. The service model including staffing, the scope of services, the forms of contract, compensation policy, performance assessment and so on has been discussed [9] and will be implemented in the whole city of Shanghai in 2013, which will further improve the efficiency of community health service in Shanghai.

\section{Conflict of interest}

The authors declare no conflict of interest.

\section{References}

1. National Health and Family Planning Commission of China. Notification on Constructing National Demonstration Community Health Centers ([2011]NO. 3). 2011.

2. Mankiw G. Principles of economics. Stamford: Thomson Learning; 2008: 210-212.
3. Varian HR. Intermediate Microeconomics: A Modern Approach (Chinese version). Shanghai: Shanghai People's Publishing House; 2009.

4. LiuYJ, Liu G, Li N, Feng ZL, Hu Q. Impact of divided management on healthcare payment and income on standard community healthcare services. Chinese Journal of Health Management 2010; 5(4): 290-293.

5. Peng YC, Su N, He YJ, Liang WN. Establishment of performance appraisal indicator system for staff of community health service centers. Journal of Chinese General Practice 2011; 14 (7): 2127-2134.

6. Sun JS, editors, Intermediate Econometrics. Shanghai: Shanghai University of Finance and Economics Press, 2009.

7. Jiang Z, Chen R, Yang ZF. Present status of human resource of community health service organization in China. Journal of Chinese General Practice 2010; 13(22): 2499-2451.

8. Zhang A, Bao Y. Research on Efficiency of Chinesemedical Healthservices: Based on Analysis of C-D Production Function. European Scientific Journal 2012; 8 (30): 87-94.

9. Lang XD, Li MC. Some thought on human resource allocation of community health in China. Chinese Health 2002; 9(1): 24-25.

\section{.COCHRANE UPDATES \& NICE GUIDELINES .}

\section{THE EPILEPSIES IN CHILDREN AND YOUNG PEOPLE}

This quality standard defines clinical best practice within this topic area. It provides specific, concise quality statements, measures and audience descriptors to provide the public, health and social care professionals, commissioners and service providers with definitions of high-quality care.

This quality standard covers the diagnosis and management of the epilepsies in children and young people aged up to 18 years.

(Source: NICE Quality standards, QS27, February 2013; available at http://guidance.nice.org.uk/QS27 ) 